\title{
Stephen C. Cote. Oil and Nation: A History of Bolivia's Petroleum Sector. xxiii, 225 pages. Morgantown: West Virginia University Press, 2016. Print.
}

Aunque la influencia de la industria petrolera en Bolivia, desde sus primeros pasos a fines del siglo XIX hasta la actualidad, ha sido fundamental en la modernización económica del país y decisiva en sus luchas políticas, sobre todo en las coyunturas constitutivas del Estado y de los diversos discursos políticos "nacionalistas", el rol que ha jugado sobre aquellas cuestiones permaneció invisibilizado a través de la investigación socio-histórica inherente a la realidad boliviana durante la mayor parte del siglo XX.

Paralelamente, los abordajes socio-históricos abocados a la minería fósil en Bolivia han estado generalmente focalizados en las luchas políticas suscitadas en torno a la imposición de estrategias para explotar los hidrocarburos del país. El análisis de otros procesos socio-económicos que, a través de la política, incidieron de muchas maneras sobre su desarrollo (como las luchas obreras e indígenas exigiendo igualdad de oportunidades), salvo parciales y raras excepciones, no ha sido tomado en cuenta. Y lo mismo ha sucedido en lo concerniente al análisis de las cuestiones propiamente técnicas de la minería fósil (en otras palabras, las relativas a su naturaleza), y a la veracidad de las percepciones que los distintos actores construyeron sobre aquellas.

El petróleo, cuya existencia en Bolivia se conocía antes de su fundación, fue una suerte de curiosidad sin valor económico hasta las últimas décadas del siglo XX. No obstante, y en la medida que los "aceites minerales" cobraban importancia comercial en el mundo como fuente de 
luz, algunos hacendados asentados en los territorios "fronterizos" del sureste boliviano comenzaron a adquirir concesiones petroleras en la región buscando arrendar su explotación a industriales foráneos en un futuro no muy cercano (hay que anotar que más allá de la "frontera" situada al este y a lo largo de las estribaciones andinas bolivianas se extendían los denominados "territorios de colonias" que habitaban las numerosas naciones de tierras bajas o los "bárbaros", como los colonos blancos y mestizos les decían).

Los primeros intentos productivos surgieron en la ciudad de Sucre mediante las gestiones del Dr. Manuel Cuéllar y el Sr. Ernesto Reyes. En 1898 Cuéllar, quien había avistado manantiales naturales de petróleo en las serranías subandinas mientras exploraba para el gobierno boliviano los territorios del Chaco Boreal en disputa con el Paraguay, junto a Reyes, quien había realizado algunos estudios topográficos independientes sobre zonas subandinas con potencial petrolero, fundaron la sociedad Cuéllar y Reyes (C\&R) con el objetivo de producir kerosén para iluminar Sucre. Acompañando los legítimos fines de lucro, la C\&R pretendía servir a su patria o "nación" creando industrias para modernizarla y sentar soberanía en sus territorios de "colonias" (es posible deducir que las experiencias amargas subsecuentes a las pérdidas del Litoral y del Acre como desenlace de las guerras del Pacífico (1879-1883) con Chile y del Acre (1900-1901) con Brasil, enseñó a las elites bolivianas que la soberanía, más allá de todo derecho nominal, como el uti posedetis juris, implicaba control del territorio).

Desarrollar la minería fósil implicaba vertebración vial y diversificación industrial, pero ¿cómo vincularla a la nación? Abriendo el Capítulo I, Cote indica: "Cuéllar tenía un intenso sentimiento nacionalista en un país profundamente dividido en razas, etnias, clases y regiones", concluyendo que Bolivia era "cualquier cosa" menos nación (1. Mi traducción). A continuación, discute los obstáculos medioambientales y sociales que se interponían en la "conquista" del petróleo que impulsaban los pioneros, los recursos que tenían para ello y la influencia de sus gestiones sobre la política pública y el nacionalismo petrolero. No sólo era preciso explorar y perforar en regiones remotas, sino también construir caminos e instalaciones. A pesar de su perseverancia y tenacidad, los pioneros carecían del capital y la técnica necesarias para esos afanes, siendo los obstáculos -evidencia Cote- insuperables con los medios que tenían (22). 
Durante años, los empresarios petroleros nativos pidieron apoyo gubernamental implementando instituciones de exploración geológica y obras de vialidad para el sector, pero los gobiernos continuaron fomentando únicamente a la minería del occidente del país con sus escasos recursos y promoviendo el desarrollo de la minería fósil mediante la inversión extranjera. ¿Por qué? La indolencia estatal frente a esos requerimientos ha sido atribuida a la pobreza congénita del tesoro público, a los vínculos de los gobiernos liberales con la gran minería estañífera, y la urgencia por sentar soberanía en los territorios de colonias adjudicando la explotación de sus recursos naturales al capital extranjero (al respecto, consultar el trabajo de Juan Anaya, Estado y Petróleo en Bolivia (19212016), tesis de doctorado en ciencias sociales, FLACSO Argentina, 2016).

Junto a estos argumentos Cote incluye, con sólida fundamentación documental, los prejuicios racistas de las elites bolivianas entre las causas centrales de aquella desidia (24). En efecto, los liberales y conservadores de la época, siguiendo al darwinismo social, atribuían el atraso industrial del país a la composición racial, mayoritariamente indígena, de sus habitantes.

Oil and Nation sustenta tres argumentos principales: 1) Los valores propios de los mercados capitalistas europeos y norteamericanos que palpitan en la identidad camba o en el habitante del oriente boliviano, son un resultado de la influencia cultural de la Standard Oil Company. 2) El petróleo causó la Guerra del Chaco, pero no en los modos que alegan las populares teorías de la conspiración. 3) Tanto el petróleo, como su explotación estatal, abonaron decisivamente la irrupción y desarrollo de la Revolución Nacional de 1952.

En su Capítulo II, Cote analiza las repercusiones que el trabajo de la Standard Oil tuvo sobre la formación social boliviana. El ingreso de la compañía en 1921, mediante un contrato jurídicamente controvertido, suscitó virulentos cuestionamientos relativos a la conveniencia de capital extranjero para explotar mineral estratégico, pero también muchas esperanzas como solución al creciente déficit energético, cuando la transición -aun inconclusa- del carbón vegetal al petróleo como base energética recién empezaba en el país (42). El autor arroja luz sobre cómo los debates políticos inherentes a la presencia de la Standard Oil en Bolivia propiciaron el surgimiento de un nacionalismo petrolero y sobre cómo, apartir de 1928, las expectativas opuestas de la compañía norteamericana 
y el gobierno boliviano concernientes al suministro interno, acarrearon los primeros litigios judiciales de ambas partes en torno a la escala impositiva que debía aplicarse a la empresa (si a la fase de exploración, o a la de producción). El aporte más significativo de este capítulo, sin embargo, implica una cuestión hasta el momento inadvertida, que constituye uno de los argumentos principales del libro: el hecho de que las operaciones de la Standard Oil en el sureste moldearon conflictos regionales entre el oriente y el occidente boliviano, instituyendo una identidad "separada" en el oriente con base en el ethos occidental que trajo la Standard $(31,57,62)$. Aunque los antagonismos oriente-occidente existían antes de la entrada de la compañía al país, sin duda Oil and Nation ofrece hallazgos decisivos para comprender mejor la historia de los conflictos regionales de Bolivia.

A lo largo del capítulo III, el autor discute su segundo argumento principal. Cabe introducir algunos elementos contextuales antes de su análisis. La Revolución Nacional de 1952, como la mayor transformación social del siglo XX en Bolivia, surgió de los sufrimientos que los soldados y oficiales medios vivieron en la Guerra del Chaco, que a mediados de 1932 comenzó en laguna Pitiantuta, o Chuquisaca, y acabó tres años más tarde con el ejército boliviano defendiendo los campos de la Standard Oil, a 500 $\mathrm{Km}$. de los primeros campos de batalla. El inesperado y nefasto desenlace para Bolivia desnudó las contradicciones e incapacidad del régimen oligárquico, socavando su legitimidad y sembrando una conciencia nacional masiva y con sentidos inéditos. Los excombatientes regresaban con dramáticos anhelos de renovación nacional ¿Qué papel jugó el petróleo y las petroleras en el conflicto? ¿Cómo incidieron sobre la formación de la conciencia nacional y las luchas políticas de la postguerra?

Cote muestra cómo el potencial petrolero para diversificar la economía y modernizar el país indujeron al Estado boliviano a ocupar militarmente el Chaco buscando una salida al Océano Atlántico para su exportación, entre otros objetivos complementarios, a través del Río Paraguay (69). Dos hechos externos arreciaron esos afanes: 1) La negativa de Argentina a la solicitud boliviana del tendido de un oleoducto por su territorio para exportar la producción de la Standard Oil, en 1930. 2) El enclaustramiento marítimo definitivo subsecuente al tratado chilenoperuano de 1929, que negó a Bolivia una salida soberana al Pacífico (79). Paraguay, en un marco diplomático bilateral malogrado, actuó similarmente.

Para la Standard Oil Co., sin embargo, los precios y la demanda del 
petróleo no justificaban los costos de transporte (apuntando a su comercialización en el país o en el marcado mundial) saliendo al Atlántico por el Chaco Boreal. Tampoco le interesaba la Ilanura chaqueña, cuyo potencial petrolero había descartado. Al contrario, estallado el conflicto bélico, se declaró neutral, negándose a incrementar el suministro interno (pese a que, de acuerdo al contrato, hacerlo era su obligación en caso de guerra) o prestar cualquier otra colaboración al país (80). Incluso llegó a vender petróleo al Paraguay a través de su filial argentina (88).

Aquel aforismo de la primera guerra mundial: "una gota de petróleo equivale a otra de sangre" también vale para la guerra del chaco. Bolivia marchó a la lucha con sólo un $10 \%$ o 15\% de su demanda petrolera cubierta con producción propia. En los hechos, las tropas bolivianas dependían de los camiones que repartían turriles de agua entre los puestos de combate, forzando esto a importar gasolina. Más aún, los soldados, mayoritariamente indígenas del Altiplano y los valles andinos, muchas veces no resistían el ambiente del Chaco. Miles murieron sin entrar en acción. Además, los caminos eran deficientes y la logística desastrosa.

Mientras militares y políticos del régimen se responsabilizan mutuamente por el curso nefasto de la lucha, entre los grupos izquierdistas emergentes y varios sectores conservadores y derechistas, la Standard Oil surgía como un enemigo común o chivo expiatorio, encarnando las culpas por la guerra. En ese contexto, y en plena guerra, las denuncias conspirativas del senador estadounidense de Louisiana, Huey Long, alias Kingfish, acusando a la Standard de empujar a Bolivia al conflicto bélico para obtener acceso a la explotación y transporte de petróleo por el Chaco, abonaron la construcción masiva de ese "mito" entre "moros y cristianos" de ambos bandos. Cabe destacar la recopilación de Cote sobre las numerosas teorías conspirativas que circularon explicando la guerra (8487). Ya en la postguerra, esos "mitos", serían decisivos para deslegitimar al régimen oligárquico y la utilidad de la inversión extranjera (90-91).

En el capítulo IV, Cote analiza las consecuencias del conflicto bélico en la minería fósil. Muestra que, al concluir la guerra, la Legión de Excombatientes (LEC), como un actor nuevo, masivo y notoriamente independiente de la oligarquía, exigía derechos ciudadanos para la clase "campesina" (indígenas), obrera y los sectores vulnerables del pueblo, pero sobre todo, estatizar el petróleo y juzgar militarmente a la Standard Oil. ¿Por qué estatizar la industria petrolera, cuya importancia económica 
era minúscula en relación a la gran minería estañífera? Cote explica que, junto a la propia naturaleza del petróleo como recurso estratégico, estaba el carácter sagrado que había adquirido entre los soldados al literalmente salvarles la vida en el epílogo de la lucha.

El caso de las exportaciones petroleras irregulares de la Standard Oil entre el sur boliviano y el norte argentino (a través de un oleoducto clandestino de $2 \frac{1}{2}$ pulgadas y supuestamente sólo de 1926 a 1927), que salió a luz pública a fines de 1935, arreció el odio a la compañía. El movimiento de oficiales articulados a la LEC y sectores civiles contestatarios, autodenominado "socialismo militar", que tomó el poder en 1936, creó Yacimientos Petrolíferos Fiscales Bolivianos (YPFB) ese mismo año y, meses después, confiscó todos los activos de la Standard arguyendo fraude fiscal por exportaciones "clandestinas" como principal fundamento legal. YPFB heredó esos activos. Cote ilumina los vericuetos legales del juicio subsecuente a la "nacionalización" (así denominó la Standard la confiscación), cuyo desenlace, a inicios de 1939, fue contra la empresa.

El autor también aborda el rol geopolítico del petróleo en la postguerra y el difícil desarrollo inicial de YPFB. Observa que: 1) la "nacionalización" de la Standard Oil Company fue la primera importante de América Latina y un revés para la política exterior del "buen vecino", 2) las nuevas fronteras de Paraguay y Bolivia se trazaron reconociendo la soberanía boliviana sobre los territorios petrolíferos, 3) el petróleo facilitó créditos extranjeros de fomento y 4) en 1941, para satisfacer a EE.UU., Bolivia indemnizó a la Standard con un monto de US\$ 1.750.000, equivalente aproximadamente al $10 \%$ de sus inversiones. A cambio, la Standard remitió a YPFB su información geológica sobre Bolivia.

YPFB nació prácticamente sin capital ni cuadros técnicos. Sólo los gobiernos articulados al nacionalismo del Chaco, especialmente los de Germán Busch (1937-1939) y Gualberto Villarroel (1943-1946), apoyaron la institución. Los vinculados a la oligarquía, en cambio, fueron negligentes ante sus problemas. La petrolera estatal sobrevivió por el compromiso de su personal con la causa de la empresa: modernizar Bolivia con justicia social en lugar de acrecentar la fortuna de los Rockefellers del mundo (120). Aunque YPFB se edificó con base en la información geológica recuperada de la Standard, fueron las inversiones que Gualberto Villarroel obtuvo para la empresa, con créditos de EE.UU., las que la consolidaron como dínamo de la liberación económica boliviana. El Movimiento Nacionalista Revolucionario (MNR) glorificó a Villarroel después de su trágica 
“inmolación por Bolivia", convirtiendo a YPFB en el legado de su sacrificio.

Cote desarrolla el tercer argumento principal de Oil and Nation en su Capítulo V: El petróleo y su explotación. Tanto como ingrediente simbólico del discurso nacionalista, como ingrediente material de la modernización, el petróleo y su explotación fueron decisivos no solo para propiciar la Revolución Nacional de 1952, sino también para consolidarla durante sus convulsos inicios y fortalecer la ulterior implementación del ambiguo programa desarrollista del MNR. Mediante las inversiones del MNR en YPFB, con recursos de la minería nacionalizada, la empresa logró el autoabastecimiento petrolífero interno en 1954, o el denominado "año del petróleo". A la par, la reapertura de la minería fósil al capital extranjero viabilizó el reconocimiento político y la "ayuda" económica de EE.UU. a los gobiernos del MNR, a pesar de sus acciones incompatibles con las democracias occidentales -como el de la redistribución de propiedades agrícolas entre los indígenas y la nacionalización de las minas. YPFB representaba "la soberanía frente al imperialismo" y "el progreso a través de la ciencia" (138), como ilustra el mural de Solón Romero en el hall de ingreso al edificio histórico de YPFB (Figs. 1 y 2 ).

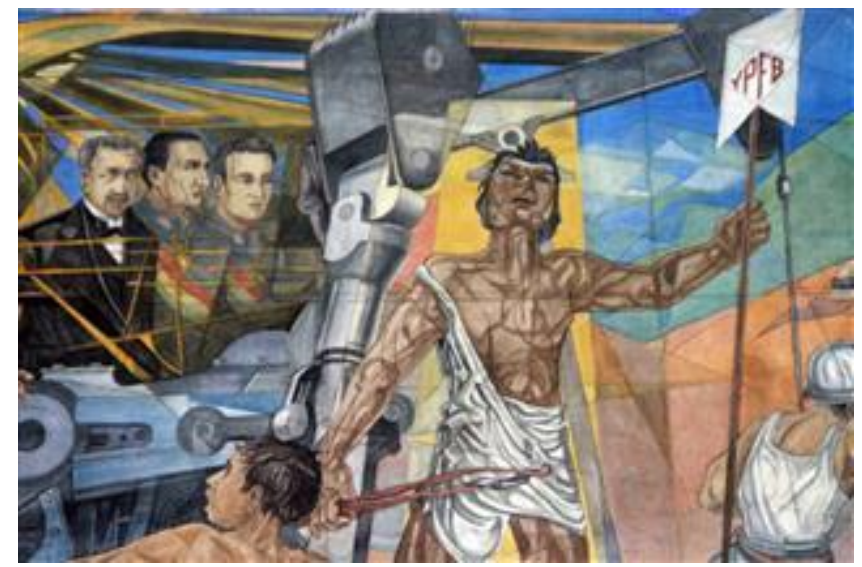

Fig.1: Detalle de "Historia del petróleo en Bolivia". Walter Solón Romero (1958) Fuente: Unidad de Comunicación Institucional, YPFB Corporación 


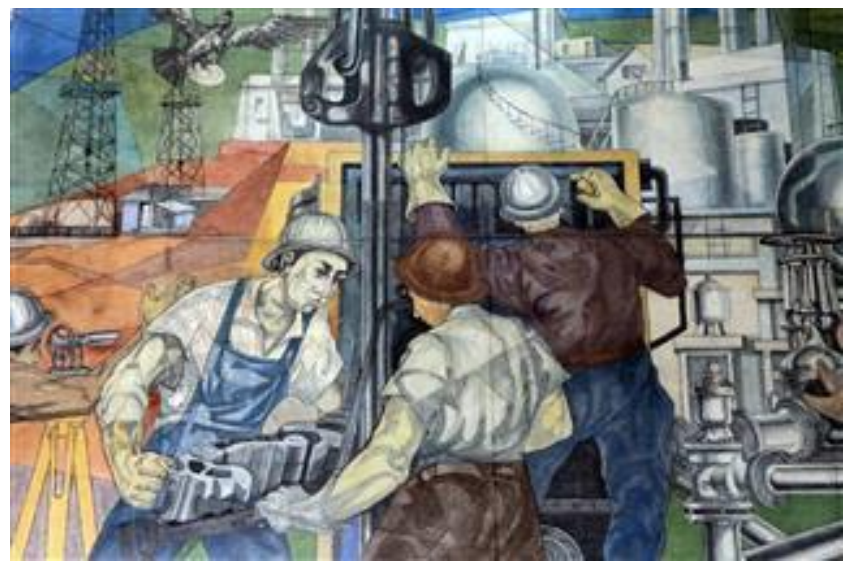

Fig. 2: Detalles de "Historia del petróleo en Bolivia". Walter Solón Romero (1958) Fuente: Unidad de Comunicación Institucional, YPFB Corporación

A la larga, los sentidos simbólicos de YPFB que el MNR afirmaba representar y la "asistencia" que recibía de los EE.UU. evidenciaron las incongruencias de su discurso político con sus políticas públicas en los hechos, soliviantando una oposición (sobre todo entre la clase obrera minera) y una eventual caída en 1964. En su Capitulo VI, Cote analiza cómo, desde entonces, las políticas públicas para la minería fósil han sido un nudo de articulación de hegemonías y contra hegemonías políticas en Bolivia.

En síntesis, la investigación de Stephen Cote, Oil and Nation: A History of Bolivia's Petroleum Sector (2016), escrita con base en su tesis doctoral The Nature of Oil In Bolivia (1898-1952), sustentada en 2013 para acceder al doctorado en historia de la Universidad de California, Davis, constituye un aporte pionero para una mejor comprensión de la historia industrial del petróleo en Bolivia y, sobre todo, de la relación entre los fines sociales o privados de su explotación, con la modernización y las transformaciones sociopolíticas del país. En ese marco, y como resultado de la incorporación del medioambiente del sureste boliviano como otro actor del drama, es decir, con agencia propia, Cote nos brinda valiosos hallazgos informativos e interpretativos.

Juan José Anaya Giorgis Universidad Mayor de San Simón (UMSS) 


\section{$(\infty))$ EY}

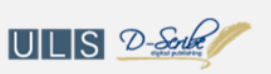

New articles in this journal are licensed under a Creative Commons Attribution 4.0 United States License.

This journal is published by the University Library System of the University of Pittsburgh as part of its D-Scribe Digital Publishing Program, and is cosponsored by the University of Pittsburgh Press. 